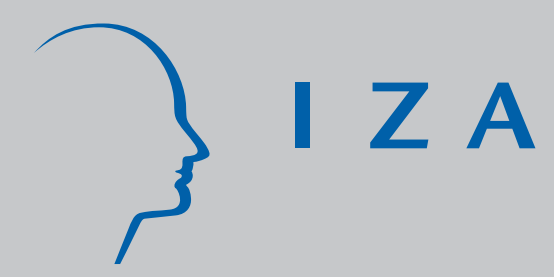

IZA DP No. 2804

Income Transfers, Welfare and Family Decisions

J oaquín Andaluz

Miriam Marcén

J osé Alberto Molina

May 2007 


\title{
Income Transfers, Welfare and Family Decisions
}

\author{
Joaquín Andaluz \\ University of Zaragoza \\ Miriam Marcén \\ University of Zaragoza \\ José Alberto Molina \\ University of Zaragoza \\ and IZA \\ Discussion Paper No. 2804 \\ May 2007 \\ IZA \\ P.O. Box 7240 \\ 53072 Bonn \\ Germany \\ Phone: +49-228-3894-0 \\ Fax: +49-228-3894-180 \\ E-mail: iza@iza.org
}

Any opinions expressed here are those of the author(s) and not those of the institute. Research disseminated by IZA may include views on policy, but the institute itself takes no institutional policy positions.

The Institute for the Study of Labor (IZA) in Bonn is a local and virtual international research center and a place of communication between science, politics and business. IZA is an independent nonprofit company supported by Deutsche Post World Net. The center is associated with the University of Bonn and offers a stimulating research environment through its research networks, research support, and visitors and doctoral programs. IZA engages in (i) original and internationally competitive research in all fields of labor economics, (ii) development of policy concepts, and (iii) dissemination of research results and concepts to the interested public.

IZA Discussion Papers often represent preliminary work and are circulated to encourage discussion. Citation of such a paper should account for its provisional character. A revised version may be available directly from the author. 


\section{ABSTRACT}

\section{Income Transfers, Welfare and Family Decisions ${ }^{*}$}

This paper studies the effects of different income transfers on individual welfare, in both marriage and divorce situations, and on family decisions. We assume three generations within the family. We develop a sequential game that, in a first stage, determines the optimum level of the transfer within a relationship of one-sided altruism. In the second stage, the level of welfare is deduced by way of a Nash bargaining solution. We show that intergenerational transfers may produce losses derived from the marriage. We have also found that the donor of an intergenerational transfer can behave in a compensatory way in an altruism model.

JEL Classification: D13, J12, D64, D10, C70

Keywords: $\quad$ income transfers, welfare, marriage, Nash-bargaining, family decisions

Corresponding author:

José Alberto Molina

Department of Economic Analysis

University of Zaragoza

Gran Vía 2

50005 Zaragoza

Spain

E-mail: jamolina@unizar.es

\footnotetext{
* This paper was partially written while José Alberto Molina was Visiting Fellow at the Department of Economics of the University of Warwick (UK), to which he would like to express his thanks for the hospitality and facilities provided. Earlier versions of this paper have been presented at European Association of Labour Economists (EALE) Meeting-2006 (Praga, Czech Republic), at the British Society for Population Studies (BSPS) Conference-2006 (Southampton, UK), and the $1^{\text {st }}$ Workshop on Economics of the Family-2006 (Zaragoza, Spain), with all the comments made by the participants, particularly those of lan Walker, being highly appreciated. Finally, the authors would like to express their thanks for the financial support provided by the Spanish Ministry of Education and Science (Project SEJ2005-06522 and Grant FPU), and by the BBVA Foundation. The usual disclaimer applies.
} 


\section{Introduction}

Private transfers between family members are common throughout the world and are among the most important economic decisions in an intrahousehold framework. ${ }^{1}$ In particular, the study of transfers between parents and children has given rise to an abundant literature, reflected in the so-called inter-generational transfer models (see, for an excellent survey, Laferrère, 1999). These models focus on the inter-relations between parents and children from the exclusively individual point of view. To the best of our knowledge, this analysis of inter-generational transfers has not been widely extended by considering the situation whereby one or other of the individual recipients takes the decisions, in turn, by way of bargaining with his/her spouse. ${ }^{2}$

It is generally accepted that the microeconomic analysis of family decisions has its origins in the household members' consensus model of Samuelson (1956). Some years later, Becker (1974) considered that the family includes a benevolent individual, for example, the head of the family, whose preferences represent the family welfare. This approach ignores one important aspect, namely the intra-family allocation of resources: the influence of an increase in family resources on the allocation within the family does not dependent on who is the recipient of these resources. For example, a family allowance programme will have the same distributive impact on the family whether it is received by the father or by the mother.

Intra-family bargaining models give explicit consideration to intrafamily allocation, including non-cooperative models (Lundberg and Pollak, 1994) and cooperative models (McElroy and Horney, 1981; Manser and Brown, 1980). In the particular case of the collective approach (Chiappori, 1988, 1992), the cooperative models are dominant in the family bargaining literature. In the cooperative equilibrium, control of resources on the part of each member is a crucial aspect in the bargaining process, and has a clear effect on family allocation. Thus, incomes received by husband and wife have separate impacts. The results of

\footnotetext{
${ }^{1}$ Existing studies of the importance of private transfers are, for example, Kotlikoff and Summers (1981), Gale and Scholz (1994) and Guiso and Jappelli (2002). Kotlikoff and Summers (1981) estimate that four-fifths of wealth comes through private transfers. Gale and Scholz (1994), using data from the 1983 wave of the Survey of Consumer Finances, report that inter-vivo transfers are the source of at least 11 percent of aggregate net worth. Guiso and Jappelli (2002), using data from Italy, found that 25.9 percent of households received transfers over their lifetime and one-third of Italian homeowners inherited their house, or received financial support in making the purchase.

${ }^{2}$ We can point to the work of Suen et al. (2003) and Andaluz and Molina (2007) as rare exceptions.
} 
the bargaining depend on the threat point that is fixed, that is to say, the status quo, which is itself conditioned by the allocation of resources between agents. Traditionally, family bargaining models have identified this threat point with divorce (Manser and Brown, 1980; McElroy and Horney, 1981). However, divorce is not the only threat point possible in a family bargaining model. More recently, for example, a number of papers have appeared in which the status quo is defined by a noncooperative equilibrium, internal to the marriage (Lundberg and Pollak, 1993; Chen and Woolley, 2001).

Following this line of thought, we analyse the effects that intergenerational transfers, public transfers and alimony have on individual welfare in both marriage and divorce situations, and on family decisions. We expand the framework of the inter-generational interactions by developing a family bargaining model in which one of the spouses receives a family transfer. Specifically, we assume three generations within the family, with only two adult generations living in independent households. As in Chami (1998) and Chami and Fisher (2000), the grandparent is not only altruistic, but has, in addition, certain expectations for the son/daughter in terms of 'merit good'. Additionally, we consider the quality of the children to be a household good. ${ }^{3}$ We assume that the quality of the child is enjoyed in common and neither ex-spouse can be excluded in the situation of divorce. We focus on the case of joint custody. ${ }^{4}$ Each agent will then choose between their own private consumption, or the household good, in both marriage and divorce situations.

As regards the main results, we should first mention that an increase in the amount of the inter-generational transfer may reduce the value of marriage compared to divorce, even if the inter-generational transfer in marriage is greater than that in divorce. Secondly, we suggest that observing the relationship between the recipient's pre-transfer income and the inter-generational transfer is not sufficient to deduce that altruistic motives or exchange motives are at work, since we observe a compensatory behaviour of the grandparent. In this case, a public transfer, which may be received by agent one in divorce, does not crowd out intergenerational transfer in marriage, even if the inter-generational transfer generates losses derived from the marriage for both spouses. Finally, an alimony, which is fixed in the situation of divorce, may have an impact on the inter-generational transfer in the situation of marriage. In this case,

\footnotetext{
${ }^{3}$ Rasul (2006) developed a model to study the investment in child quality during marriage and, at divorce, child custody. In the economics literature, child custody and its effect on child quality has received little attention.

${ }^{4}$ Rasul (2006) showed that for couples with homogeneous valuations of the child, joint custody is optimal.
} 
the grandparent does not always compensate the son/daughter in the situation of marriage, equalizing the income of this agent in situations of both marriage and divorce.

The paper is organised as follows. In Section II we provide an overview of the theoretical literature and empirical studies on private transfers. In Section III we describe both the model employed in the study and the resolution process. Section IV is devoted to an analysis of the most important results. Finally, Section V closes the paper with a review of the main conclusions and the possible extensions of the work.

\section{Literature}

What motivates individuals to transfer income to family members? The private transfer literature contains several alternative answers. Motives are mixed in the population and it is difficult to select a single motive, since strategic considerations may play a role in some families.

Arrondel and Laferrère (2001), based on the 'Actifs financiers' survey, describe motives as organizing the sharing between the children, the fiscal motive, the altruistic motive, the gift after a windfall gain, the motive of the survival of the family firm, and the motive of giving on retirement. Cox (1990) has described an alternative motive: he argues that inter-vivo transfers help individuals who are constrained to increase current consumption.

Arrondel and Masson (2001) and Güth et al. (2004) consider that interaction among family members of different generations is often characterized by reciprocity - i.e. indirect reciprocity (the recipient does not give back to the initial giver, but to a third person) and direct reciprocity (the recipient is kind to the donor in relation to how kind the donor is to the recipient). Güth et al. (2004) found little evidence of direct reciprocity, whereas Arrondel and Masson (2001) showed that for each transfer, parents are strongly influenced by the corresponding behaviour of their own parents. Cox and Stark (2005) consider the demonstration-effect hypothesis. They document that tied transfers for housing constitute an encouragement by the donor, to the recipient, for the production of children.

Many studies seek to test among competing motives for private transfers. In the studies on private transfer, the bulk of the literature focuses on two main competing hypotheses; altruism (Becker, 1991) and exchange (Bernheim et al., 1985, Cox 1987). According to Cox (1987), the key to identifying transfer motives is the relationship between the recipient's pre-transfer income and the transfer amounts received. 


\subsection{Altruism and Exchange}

Modern analysis of altruism stems from Becker's (1974) research on social interactions. Becker introduced altruism in the context of the preferences of parents regarding their children's consumption. He explains that a parent is effectively altruistic towards another member of the family, (i.e. the children), when the parent's utility function depends positively on the well-being of the children, and that the parent's behaviour is changed by his/her altruism (Becker, 1981).

Becker characterized the family as income-equalizing, where transfers are used to equate the donor's marginal utility of consumption with the recipient's marginal utility of consumption from the donor's perspective; i.e. transfers tend to equalize the resources of the donor and the recipient.

With family income held constant, the altruism model predicts that an increase in the recipient's income is met with a reduction in transfers received, suggesting a compensatory role for these transfers. Altruism is found when the recipients are young adults, but altruism is difficult to detect when we analyse total private transfers. For example, Kang and Lee (2003) and, Kang and Sawada (2003) show that private transfer is altruistically motivated in Korea.

Some authors emphasize the importance of interdependent preferences, for example Bergstrom (1999), who also studied systems of utility functions in which each individual's utility does not solely depend on his or her own private consumption (systems of interdependent utility functions are normally considered benevolent). ${ }^{5}$

Several other empirical studies have tested and rejected other predictions of the altruism model. Altruism seems to be found when the children are young adults, and is linked to gifts of comparatively small amounts. Altruism is harder to identify from studies of total inter-vivo transfers (see Arrondel and Lafèrrere, 2001).

Another body of research treats family members as nonaltruistic (see Cox, 1987). Transfers from the parent are a means of purchasing services from the children; that is, transfer is a means of paying for care from one's children and the parent may use gifts or a promise of inheritance as payment for a child's 'attention' or support during their old age (Kotlikoff and Spivak, 1981; Bernheim et al., 1985 and Cox, 1987).

In the exchange model, Cox (1987), considers two individuals, a

\footnotetext{
${ }^{5}$ 'A system of interdependent utilities with private subutility functions $u_{i}\left(c_{i}\right)$ and interdependent utility functions $U_{i}=F_{i}\left(u_{i}\left(c_{i}\right), U_{-i}\right)$ is normally benevolent if it induces a unique system of independent utility functions $G_{i}: C_{i} \rightarrow \Re$ for $i \in S$ such that $G_{i}(c)=F_{i}\left(u_{i}\left(c_{i}\right), u_{-i}\left(c_{-i}\right)\right)$., where each $G_{i}$ is a monotone increasing function of each of the $u_{j}$ 's.' (Bergstrom, 1999).
} 
donor (the parent) and a recipient (the child). The parent cares about the well-being of the child. In addition, the child provides services to the parent. The exchange motive admits a positive relationship between the recipient's income and the transfers received. The child's market opportunity cost rises, the parent has to compensate the child for spending more time with the parent by increasing the transfers.

\section{Crowding-out}

Understanding private transfer is important because operative intergenerational transfers can neutralize the effects of some government policies. Many governments apply public programs to the achievement of social objectives. Changes in private inter-household transfers could render public welfare programs ineffective, because the crowding-out effect implies that public transfers do not change the total income. Ignoring crowding-out may overstate the effects of these public programs.

Barro (1974) and Becker (1974) have studied the crowding-out hypothesis. The distributional effect of these policy changes depends on the motivation of intergenerational transfers. On the one hand, altruistically motivated private transfers can neutralize completely the effects of public transfer. Kang and Lee (2003) and Kang and Sawada (2003) use the Korean Household Panel Survey (KHPS) data, and they find a strong crowding-out relationship between private and public transfers. Jensen (2003) focuses on an increase in state old-age pensions in South Africa and finds that government pensions for the elderly lead to a reduction in the level of private transfers received from children living overseas as migrants. Güth et al. (2004) study crowding-out in an experimental setting. They see that transfers to the young are crowded out, but crowding out is less than complete. Villanueva (2005) documents that inter-vivo transfers may displace public assistance: he finds that the impact is higher in the United States than in West Germany, and that crowding-out is less than complete in both cases.

On the other hand, if exchange-motivated transfers interact with public transfers, crowding-out between private and public transfers does

not necessarily occur. For example, Cox et al. (1998) find that public income redistribution might not be neutralized by private-transfers.

\section{The Primary Model}

Let us consider a model of one-sided altruism in which there is the donor of a transfer, the grandparent, and the recipient of that transfer, his son/daughter. Let $U_{p}\left(\mathbf{C}_{\mathbf{p}}, W_{1}\left(\mathbf{x}_{\mathbf{1}}, W_{2}\right), q_{1}\right)$ be the utility functions of the grandparent where $u_{p}: \Re_{+}^{n} \rightarrow \Re$ is the grandparent's subutility function, and where $\Re$ is the set of real numbers. The argument 
$\mathbf{C}_{\mathbf{p}} \in \Re_{+}^{n}$ of the utility function is a vector of $n$ goods consumed by the grandparent, $W_{1}$ and $W_{2}$ represent the utility of spouse one, that is, his/her son/daughter, and the utility of spouse two, respectively, $q_{1}$ corresponds to the level of provision of the quality of the grandchild and $\mathbf{x}_{1}=\left(X_{1}, q_{1}\right)$, where $X_{1}$ is the private consumption of spouse one. ${ }^{6}$ We further assume that $U_{p}$ is strictly quasi-concave, increasing with respect to the goods consumed, the level of provision of the grandchild's quality and the utility of spouse one.

We suppose that both spouses are symmetrics, both get utility from the private consumption and the household good and that there is mutual altruism between them. Therefore, $W_{i}=W_{i}\left(V_{i}, V_{-i}\right)$, where $V_{i}=$ $V_{i}\left(\mathbf{x}_{\mathbf{i}}\right)$, with $\mathbf{x}_{\mathbf{i}}=\left(X_{i}, q_{i}\right), i=1,2$. In our case, both agents contribute to the commodity q.Spouses take the effects of their actions into account. So, child development affects the parental allocation of resources. Each agent has a perfect knowledge of the preferences of the other.

The modelling of a two-stage sequential game allows us to endogenously deduce the amount of the transfer, and study the relationship between the recipient's income sources and the transfer amount received. Applying the backward induction procedure, we begin by obtaining the equilibrium corresponding to the second stage, in which the optimum provision of the household good is determined. Subsequently, we obtain the optimum level of transfer fixed by its donor.

In the second stage of the game, the levels of private consumption of the son/daughter, and the provision of the household good are determined by way of a bargaining process between each agent and his/her spouse. Hence, given the exogenous variables, if we want to predict how a household will behave, we have to identify the household equilibrium $\left(\mathbf{x}_{\mathbf{i}}^{*}, \mathbf{x}_{-\mathbf{i}}^{*}\right), i=1,2$.

We need a cooperative bargaining model to study what happens after a complex social interaction, which includes the ability of the players to punish one another. Then, the allocation of the welfare between both spouses is the result of obtaining the symmetric Nash bargaining solution. The equilibrium is obtained by resolving the following maximisation problem:

$$
\underset{W_{1}, W_{2}}{\operatorname{Max} . J}=\left(W_{1}-\tilde{V}_{1}\right)\left(W_{2}-\tilde{V}_{2}\right)
$$

where $\tilde{V}_{i}, i=1,2$, denotes the level of utility obtained at the threat point. The utility a spouse receives in the Nash bargaining solution is an

\footnotetext{
${ }^{6}$ We assume that $q_{1}$ is the grandchild's development, which is the result of the contribution of spouse one to the grandchild's quality, thus it enters the grandparent's utility directly and indirectly through its effect on the utility of spouse one.
} 
increasing function of the utility the spouse receives at the threat point. From the first order condition of that problem, we obtain the optimum level of utility of spouse two, $W_{2}^{*}$ which, in turn, determines the level of utility of spouse one, $W_{1}^{*}$.

We assume that the dissolution of the marriage represents the threat point of the bargaining. However, we must take into account that, in the situation of divorce, each ex-spouse may influence child development, and that this may affect the utility of the other ex-spouse. Therefore, either of the agents obtains utility from the contribution to the household good by the other, after the marriage has been dissolved. In this situation, there is no mutual altruism. Then the utility functions of the spouses will take the following expressions: $V_{i}=V_{i}\left(q_{i}, q_{-i}, X_{i}\right), i=1,2$.

The optimum behaviour of each of these two agents in the situation of divorce consists in determining the level of provision of the household good, $\left(\tilde{q}_{1}, \tilde{q}_{2}\right)$, that maximises his/her individual utility, given the budget constraint. Applying that process it is straightforward to obtain the optimum levels of the utility of both ex-spouses in equilibrium, $\left(\tilde{V}_{1}, \tilde{V}_{2}\right)$.

We then analyse the equilibrium corresponding to the first stage of the game. We must distinguish between both marriage and divorce situations by determining the behaviour of the grandparent at the threat point, and the behaviour of the grandparent when agent one is married, with the objective being to specify an amount of transfer that maximises individual utility subject to the budget constraint. Formally:

$$
\begin{aligned}
& \underset{T}{\operatorname{Max}} U_{p}\left(\mathbf{C}_{\mathbf{p}}, \bar{V}_{1}, q_{1}\right) \\
& \text { subject to } \sum_{j=1}^{n} C_{p j}=y_{p}-T
\end{aligned}
$$

where $\bar{V}_{1}=W_{1}^{*}$ and $q_{1}=q_{1}^{*}$ in the situation of marriage and $\bar{V}_{1}=$ $\tilde{V}_{1}$ and $q_{1}=\tilde{q}_{1}$ in the situation of divorce, with $\mathrm{y}_{p}$ representing the income level of the grandparent. Solving this maximisation problem, we determine the optimum level of the inter-generational transfer in the situation of marriage $T^{*}$ and in the situation of divorce $\tilde{T}$. Therefore, given that the utility of agent one in the situation of marriage and in divorce is different, the grandparent's optimum amount of transfer is different in both situations. ${ }^{7}$

We can now explore the implications of our model of inter-generational behaviour in various special contexts. The purpose of the next Section is to study the implications of this game-theoretic framework for individual welfare and for inter-generational transfer equilibrium.

\footnotetext{
${ }^{7} T^{*} \neq \tilde{T}$ when $W_{1}^{*} \neq \tilde{V}_{1}$ and $\tilde{q}_{1} \neq q_{1}^{*}$.
} 


\subsection{An Example}

Let $U_{p}$ be the utility of the grandparent, which for the sake of simplicity we suppose to be additive and of the form:

$$
U_{p}\left(C_{p}, W_{1}, q_{1}\right)=u_{p}\left(C_{p}\right)+\beta_{p} W_{1}\left(\mathbf{x}_{1}, W_{2}\right)+g\left(q_{1}\right)
$$

where $u_{p}$ denotes the levels of sub-utility and $\beta_{p} \in(0,1)$ indicates the degree of altruism of the grandparent. The grandparent's attitude towards the development of the grandchildren, which is the result of decisions taken by spouse one, is captured by $g: \Re_{+} \rightarrow \Re_{+}$, which is the grandparent's "merit good" function, which is a concave and strictly differentiable function, and $g^{\prime}(0)=0$.

For a simple example, we consider the following utility functions of both spouses, which are a case of the "separate spheres" model (Lundberg and Pollak, 1993), to carry out comparative static analyses. Further, we suppose that both agents are symmetric, both get utility from the private consumption and the household good, and there is mutual altruism between both spouses. Formally,

$$
W_{i}=V_{i}+s_{i} V_{-i}, \quad i=1,2,0<s_{i}<1
$$

where $V_{1}$ and $V_{2}$ represent the sub-utility functions of spouse one and spouse two, respectively:

$$
V_{i}\left(q_{i}, q_{-i}, X_{i}\right)=X_{i} q_{1}^{\alpha} q_{2}^{1-\alpha}, i=1,2.0<\alpha<1
$$

where $X_{i}, i=1,2$, denotes the private consumption of each spouse and $q_{i}$ the household good. ${ }^{8}$ In our case, $q_{i}$ is provided by the market. ${ }^{9}$

With $T$ and $r$ being the intergenerational transfer, and a transfer made by one spouse to the other, respectively (we assume that $r$ is donated by 2 and received by 1 ), and where $Y_{i}$ represents the non-labour income of each spouse, the private consumption can be given as $X_{1} \leq$ $Y_{1}+T-P_{1} q_{1}+Z_{1}+r$ and $X_{2} \leq Y_{2}-P_{2} q_{2}-r+Z_{2}$ where $Z_{i}, i=1,2$ are public transfers and let $P_{i}, i=1,2$ be the price of the commodity $q$ for each spouse. ${ }^{10}$

\footnotetext{
${ }^{8}$ Gronau (1973) and Ben-Porath (1973), among others, have adapted the framework of Becker (1965) and modeled child care as a home-produced good using two inputs: the parents' time and market inputs.

${ }^{9}$ For the sake of simplicity, we assume that $\frac{\partial V_{i}}{\partial X_{i}}=\frac{\partial V_{-i}}{\partial X_{-i}}, i=1,2$, because of the consideration of symmetric individuals.

${ }^{10}$ In the situation of marriage the results do not change if the trasfer is donated by 1 and received by 2 . We also suppose that $P_{i} \neq 0, i=1,2$.
} 
The utility possibilities frontier is defined by way of the following conditioned optimisation programme, which can be written very simply as:

$$
\begin{aligned}
& \underset{\mathbf{x}_{1}, \mathbf{x}_{2}}{\operatorname{Max}} W_{1}=W_{1}\left(V_{1}, V_{2}\right) \\
& \text { subject to } \\
& X_{1} \leq Y_{1}+T-P_{1} q_{1}+Z_{1}+r \\
& X_{2} \leq Y_{2}-P_{2} q_{2}-r+Z_{2} \\
& W_{2}=W_{2}\left(V_{2}, V_{1}\right)
\end{aligned}
$$

Let us describe the solution to this maximization problem as: ${ }^{11}$

$$
\begin{aligned}
q_{i}^{*} & =q_{i}^{*}\left(\Omega, \alpha, P_{i}\right), i=1,2 \\
X_{i}^{*} & =X_{i}^{*}\left(Y_{1}, Y_{2}, \alpha, T, Z_{1}, Z_{2}, P_{i}, r\right)
\end{aligned}
$$

where $\Omega=Y_{1}+Y_{2}+T+Z_{1}+Z_{2}$, that is, the total income of the household in the situation of marriage. The investment in quality of the child, $q_{i}^{*}$, depends on the total income, on the weight each agent assigns to the child output, and on the prices of the household good.

Introducing the optimum values in the objective function of the above maximisation problem, we determine the set of efficient allocations or Utility Possibilities Frontier (UPF):

$$
W_{1}^{U P F}=W_{1}\left(Y_{1}, Y_{2}, T, W_{2}, Z_{2}, Z_{1}, \alpha, s_{1}, s_{2}\right)
$$

As stated earlier, the allocation of resources between the spouses follows a bilateral bargaining process; more specifically, the equilibrium $\left(W_{1}^{*}, W_{2}^{*}\right)$ is obtained by resolving the $(1)$ maximization problem. The first order condition of that problem is given by:

$$
-W_{2}+\tilde{V}_{2}-\frac{1}{\frac{\partial W_{1}^{U P F}}{\partial W_{2}}}\left(W_{1}-\tilde{V}_{1}\right)=0
$$

where $\frac{\partial W_{1}^{U P F}}{\partial W_{2}}$ is the slope of the utility possibilities frontier.

The utility functions of the spouses in the situation of divorce adopt this expression:

$$
V_{i}\left(q_{i}, q_{-i}, X_{i}\right)=X_{i} q_{1}^{\alpha} q_{2}^{1-\alpha}, i=1,2 .
$$

Given that $\Omega_{d 1}=Y_{1}+T_{d}+Z_{1}-r_{d}$ and $\Omega_{d 2}=Y_{2}+Z_{2}+r_{d}$ represent the total income for each ex-spouse in the situation of divorce, where $r_{d}$ is a transfer made by one spouse to the other, which we suppose is fixed exogenously. In this case, this transfer affects the decisions taken

\footnotetext{
${ }^{11}$ Note that Second order condition is satisfied.
} 
by both ex-spouses. From this we can easily determine the optimum behaviour of each of the ex-spouses. For each ex-spouse, we can express the optimum equilibrium as:

$$
\tilde{q}_{i}=\tilde{q}_{i}\left(\Omega_{d i}, \alpha, P_{i}\right)
$$

and

$$
\tilde{V}_{i}=\tilde{V}_{i}\left(\Omega_{d i}, \alpha, P_{i}, \tilde{q}_{-i}\right)
$$

with $i=1,2$.

In what follows, we will analyse the equilibrium corresponding to the first stage of the game. In this stage, the grandparent decides the optimum amount of transfers $T$ to donate to the son/daughter in both marriage and divorce situations. From (2) and taking into account (3), we determine the optimum behaviour of the grandparent in the situation of divorce, ${ }^{12}$ whose first order condition is given by:

$$
-\tilde{u}_{p}^{\prime}+\beta_{p} \frac{\partial \tilde{V}_{1}}{\partial T}+g^{\prime}\left(\tilde{q}_{1}\right) \frac{\partial \tilde{q}_{1}}{\partial T}=0
$$

Furthermore, compliance with the second order condition of the above maximisation problem leads to the inequality being satisfied:

$$
\Delta_{d}=\tilde{u}_{p}^{\prime \prime}+\beta_{p} \frac{\partial^{2} \tilde{V}_{1}}{\partial T^{2}}+g^{\prime \prime}\left(\tilde{q}_{1}\right)\left(\frac{\partial \tilde{q}_{1}}{\partial T}\right)^{2}+g^{\prime}\left(\tilde{q}_{1}\right) \frac{\partial^{2} \tilde{q}_{1}}{\partial T^{2}}<0
$$

Solving (13) implicitly for $T$, we obtain $\tilde{T}$, that is, the optimum amount of transfer in divorce.

Assuming that, in the second stage, agent one is married, let us now consider the equilibrium of the first stage, whose first order condition is given by the equation:

$$
u_{p}^{\prime}=\beta_{p} \frac{\partial W_{1}^{*}}{\partial T}+g^{\prime}\left(q_{1}^{*}\right) \frac{\partial q_{1}^{*}}{\partial T}
$$

and the following expression is the second order condition which is satisfied:

$$
\Delta=u_{p}^{\prime \prime}+\beta_{p} \frac{\partial^{2} W_{1}^{*}}{\partial T^{2}}+g^{\prime \prime}\left(q_{1}^{*}\right)\left(\frac{\partial q_{1}^{*}}{\partial T}\right)^{2}+g^{\prime}\left(q_{1}^{*}\right) \frac{\partial^{2} q_{1}^{*}}{\partial T^{2}}<0
$$

Solving (15) implicitly for $T$, we obtain $T^{*}$, that is, the optimum amount of transfer in the situation of marriage.

\footnotetext{
${ }^{12}$ We focus on the case where private transfers are operative, and thus assume $y_{p}$ is sufficiently large that $T>0$ in equilibrium.
} 


\section{Results}

On the basis of the above, we are in a position to draw a series of conclusions on the influence of the amount of the transfer on welfare in both situations - marriage and divorce- and the conditions under which there is no crowding-out.

Proposition 1 For both spouses, an increase in the amount of the intergenerational transfer (the same in both marriage and divorce situations) decreases the value of marriage compared to its alternative, the divorce, when the amount of inter-generational transfer in divorce is greater than that in marriage. This also occurs when the amount of inter-generational transfer is greater in marriage than in divorce, depending on the relationship between the income of both agents, and the weight each one assigns to the child output.

Proof. Differentiating expression (9) in equilibrium, and considering equation (8), we can deduce the influence of the transfer on the level of welfare of each spouse in the situation of marriage. We thus obtain the following expressions: ${ }^{13}$

$$
\begin{gathered}
\frac{\partial W_{1}^{*}}{\partial T}=\frac{1}{2}\left[\frac{\partial W_{1}^{U P F}}{\partial T}+\frac{\partial \tilde{V}_{1}}{\partial T}+\frac{\partial W_{1}^{U P F}}{\partial W_{2}} \frac{\partial \tilde{V}_{2}}{\partial T}\right] \\
\frac{\partial W_{2}^{*}}{\partial T}=\frac{1}{2}\left[\frac{\partial \tilde{V}_{2}}{\partial T}-\frac{1}{\frac{\partial W_{1}^{U P F}}{\partial W_{2}}}\left(\frac{\partial W_{1}^{U P F}}{\partial T}-\frac{\partial \tilde{V}_{1}}{\partial T}\right)\right]
\end{gathered}
$$

We can separate the welfare impact into two components, i.e. changes along the utility possibilities frontier, and changes in the threat point. Comparing these two components, we can determine if an increase in the amount of the inter-generational transfer produces losses or gains derived from the marriage. Therefore, the effect of an intergenerational transfer on the allocation of the welfare derived from the marriage will depend crucially on the definition of the threat point implicit in the bargaining process.

For the spouse one, when $\left|\frac{\partial W_{1}^{U P F}}{\partial T}+\frac{\partial \tilde{V}_{1}}{\partial T}\right|<\left|\frac{\partial W_{1}^{U P F}}{\partial W_{2}} \frac{\partial \tilde{V}_{2}}{\partial T}\right| \rightarrow \frac{\partial W_{1}^{*}}{\partial T}<0$,

given that $\frac{\partial \tilde{V}_{2}}{\partial T}>0 ; \frac{\partial W_{1}^{U P F}}{\partial W_{2}}<0$ and $\frac{\partial W_{1}^{U P F}}{\partial T}+\frac{\partial \tilde{V}_{1}}{\partial T}>0$.Therefore, an increase in the amount of inter-generational transfer in both marriage and divorce situations generates losses derived from the marriage.

\footnotetext{
${ }^{13}$ Under the assumption that $\frac{\partial^{2} W_{1}^{U P F}}{\partial T \partial W_{2}}=0$.
} 


$$
\frac{\partial\left(W_{1}^{*}-\tilde{V}_{1}\right)}{\partial T}<0
$$

When $\left(\frac{\partial W_{1}^{U P F}}{\partial T}-\frac{\partial \tilde{V}_{1}}{\partial T}\right)>\frac{\partial W_{1}^{U P F}}{\partial W_{2}} \frac{\partial \tilde{V}_{2}}{\partial T} \rightarrow \frac{\partial\left(W_{1}^{*}-\tilde{V}_{1}\right)}{\partial T}>0$. And when $\left|\frac{\partial W_{1}^{U P F}}{\partial T}-\frac{\partial \tilde{V}_{1}}{\partial T}\right|<\left|-\frac{\partial W_{1}^{U P F}}{\partial W_{2}} \frac{\partial \tilde{V}_{2}}{\partial T}\right| \rightarrow \frac{\partial\left(W_{1}^{*}-\tilde{V}_{1}\right)}{\partial T}<0$.Both situations comply with $\frac{\partial W_{1}^{*}}{\partial T}>0$.

For spouse two, when $\left|\left(\frac{\partial W_{1}^{U P F}}{\partial T}-\frac{\partial \tilde{V}_{1}}{\partial T}\right)\left(\frac{1}{\frac{\partial W_{1}^{U P F}}{\partial W_{2}}}\right)\right|>\left|\frac{\partial \tilde{V}_{2}}{\partial T}\right|$ and $\frac{\partial W_{1}^{U P F}}{\partial T}<$ $\frac{\partial \tilde{V}_{1}}{\partial T}$ the following is satisfied: $\frac{\partial W_{2}^{*}}{\partial T}<0$.Therefore, for spouse two, an increase in the amount of inter-generational transfer in both marriage and divorce generates losses derived from the marriage.

$$
\frac{\partial\left(W_{2}^{*}-\tilde{V}_{2}\right)}{\partial T}<0
$$

When $\left|\left(\frac{\partial W_{1}^{U P F}}{\partial T}-\frac{\partial \tilde{V}_{1}}{\partial T}\right)\left(\frac{1}{\frac{\partial W_{1}^{U P F}}{\partial W_{2}}}\right)\right|>\left|-\frac{\partial \tilde{V}_{2}}{\partial T}\right|$ and $\left(\frac{\partial W_{1}^{U P F}}{\partial T}-\frac{\partial \tilde{V}_{1}}{\partial T}\right)>0$ the following expression is satisfied: $\frac{\partial\left(W_{2}^{*}-\tilde{V}_{2}\right)}{\partial T}>0$. But if $\left|\left(\frac{\partial W_{1}^{U P F}}{\partial T}-\frac{\partial \tilde{V}_{1}}{\partial T}\right)\left(\frac{1}{\frac{\partial W_{1}^{U P F}}{\partial W_{2}}}\right)\right|<$ $\left|-\frac{\partial \tilde{V}_{2}}{\partial T}\right|$ even with $\frac{\partial W_{1}^{U P F}}{\partial T}-\frac{\partial \tilde{V}_{1}}{\partial T}>0 \rightarrow \frac{\partial\left(W_{2}^{*}-\tilde{V}_{2}\right)}{\partial T}<0$. Both situations comply with: $\frac{\partial W_{2}^{*}}{\partial T}>0$.

We know analyse the variables which produce losses derived from the marriage, using our example.

From (8), we can easily obtain the equations:

$$
\frac{\partial W_{1}^{U P F}}{\partial W_{2}}=\frac{\left(1-s_{1}\right)}{\left(-1+s_{2}\right)}<0
$$

and

$$
\frac{\partial W_{1}^{U P F}}{\partial T}=\frac{\left(q_{1}^{*}\right)^{\alpha}\left(q_{2}^{*}\right)^{(1-\alpha)}\left(-1+s_{1} s_{2}\right)}{\left(1-s_{1}\right)} \frac{\partial W_{1}^{U P F}}{\partial W_{2}}>0
$$

with equation (21) being the slope of the UPF.

For ex-spouse two, differentiating expression (12) and considering equations (11), we can deduce that, at the threat point, the transfer has a positive effect on the level of utility of ex-spouse two in divorce:

$$
\frac{\partial \tilde{V}_{2}}{\partial T}=\frac{-\alpha\left(\tilde{q}_{1}\right)^{\alpha}\left(\tilde{q}_{2}\right)^{(1-\alpha)} \Omega_{d 2}}{(-2+\alpha) \Omega_{d 1}}>0
$$


Furthermore, for ex-spouse one, the influence of the transfer on the level of welfare achieved by its recipient at the threat point is given by the expression:

$$
\frac{\partial \tilde{V}_{1}}{\partial T}=\left(\tilde{q}_{1}\right)^{\alpha}\left(\tilde{q}_{2}\right)^{(1-\alpha)}>0
$$

It is straightforward to deduce the effect that a change in the amount of the transfer has on the welfare of both spouses. Subsequently, we determine the gains or losses derived from the marriage, for spouse one:

$$
\frac{\partial\left(W_{1}^{*}-\tilde{V}_{1}\right)}{\partial T}=\frac{\left(-1+s_{1} s_{2}\right)}{2\left(-1+s_{2}\right)}\left[\left(q_{1}^{*}\right)^{\alpha}\left(q_{2}^{*}\right)^{(1-\alpha)}+\Phi_{1}\left(\tilde{q}_{1}\right)^{\alpha}\left(\tilde{q}_{2}\right)^{(1-\alpha)}\right]
$$

A condition necessary but not sufficient to obtain losses derived from the marriage is that $\Phi_{1}<0$, with $\Phi_{1}=\frac{1}{\left(-1+s_{1} s_{2}\right)}\left[\left(1-s_{2}\right)+\frac{\left(-1+s_{1}\right) \alpha \Omega_{d 2}}{(-2+\alpha) \Omega_{d 1}}\right]$, which is satisfied.We also need to analyse the relationship between $\left(q_{1}^{*}, q_{2}^{*}\right)$ and $\left(\tilde{q}_{1}, \tilde{q}_{2}\right)$. If $\left(\tilde{q}_{1}\right)^{\alpha}\left(\tilde{q}_{2}\right)^{(1-\alpha)} \geq\left(q_{1}^{*}\right)^{\alpha}\left(q_{2}^{*}\right)^{(1-\alpha)}$ and $\left|\Phi_{1}\right| \geq 1 \rightarrow \frac{\partial\left(W_{1}^{*}-\tilde{V}_{1}\right)}{\partial T} \leq$ 0 .In the case that, $\left(\tilde{q}_{1}\right)^{\alpha}\left(\tilde{q}_{2}\right)^{(1-\alpha)}<\left(q_{1}^{*}\right)^{\alpha}\left(q_{2}^{*}\right)^{(1-\alpha)}$ and $\left|\Phi_{1}\right|<1 \rightarrow \frac{\partial\left(W_{1}^{*}-\tilde{V}_{1}\right)}{\partial T}>$ 0. But even with $\left(\tilde{q}_{1}\right)^{\alpha}\left(\tilde{q}_{2}\right)^{(1-\alpha)}<\left(q_{1}^{*}\right)^{\alpha}\left(q_{2}^{*}\right)^{(1-\alpha)}$ if $\left|\Phi_{1}\right|>>1$, it is possible to find losses derived from the marriage. Therefore, even when $q_{1}^{*}>\tilde{q}_{1}$ and $q_{2}^{*}>\tilde{q}_{2}$, it is possible to find losses derived from the marriage, a result that is opposite to that found by Suen et al. 2003. ${ }^{14}$

If spouse one has losses derived from the marriage, spouse two will also have losses derived from the marriage, given that $\frac{\partial\left(W_{2}^{*}-\tilde{V}_{2}\right)}{\partial T}=-\frac{1}{\frac{\partial W_{1}^{U P F}}{\partial W_{2}}} \frac{\partial\left(W_{1}^{*}-\tilde{V}_{1}\right)}{\partial T}$.

We also may deduce the expression (19) from the first order condition of the first stage of the game. Subsequently, for spouse two we may deduce the losses derived from the marrage. Formally,

$$
\frac{\partial\left(W_{1}^{*}-\tilde{V}_{1}\right)}{\partial T}=\frac{1}{\beta_{p}}\left[\left(u_{p}^{\prime}-\tilde{u}_{p}^{\prime}\right)+\left(g^{\prime}\left(\tilde{q}_{1}\right) \frac{\partial \tilde{q}_{1}}{\partial T}-g^{\prime}\left(q_{1}^{*}\right) \frac{\partial q_{1}^{*}}{\partial T}\right)\right]
$$

If $T_{d}>T \rightarrow \tilde{u}_{p}^{\prime}>u_{p}^{\prime}$. As noted above, in the case that $\tilde{q}_{1}>$ $q_{1}^{*}$ the implication is that $g^{\prime}\left(q_{1}^{*}\right)>g^{\prime}\left(\tilde{q}_{1}\right)$.In that case, we can find losses derived from the marriage if $\left(g^{\prime}\left(\tilde{q}_{1}\right) \frac{\partial \tilde{q}_{1}}{\partial T}-g^{\prime}\left(q_{1}^{*}\right) \frac{\partial q_{1}^{*}}{\partial T}\right)<0$. When $T_{d}=T$,

\footnotetext{
${ }^{14}$ Suen et al. (2003) study the implications of intergenerational transfers on the allocation of resources within a conjugal household. They work with other preferences and present a Nash-bargaining analysis of the effect of a dowry on the allocation of resources within the family with private and public consumption goods. They find that altruistic parents have greater incentive to give transfers to married daughters than to divorced daughters. However, this result is conditioned by $q_{1}^{*}>\tilde{q}_{1}$ and $q_{2}^{*}>\tilde{q}_{2}$.
} 
if $\left|-2 T_{d}+(1+\alpha) T\right|<\left|(1-\alpha) Y_{1}-(1+\alpha) Y_{2}\right| \rightarrow \tilde{q}_{1}>q_{1}^{*}$, or if $T_{d}<T$ and $\tilde{q}_{1}>q_{1}^{*}$,we can also find losses derived from the marriage.

In this situation, we are not considering the cases when $q_{1}^{*}>\tilde{q}_{1}$, which may generate losses derived from the marriage, as we have explained earlier.

From expressions (6) and (11), we may determine that marriage equilibrium investment in child quality may be below the equilibrium investment in divorce.

Corollary 2 For spouse one, $\tilde{q}_{1}>q_{1}^{*}$ when $T_{d}>T$ (for the sake of simplicity we can suppose that there are no public transfers and no transfer made by one spouse to the other in divorce) and also when $T_{d}<$ $T$ but $Y_{1} \gg Y_{2}$ and/or $\alpha \rightarrow 0$.In the case that $T_{d}<T$ but $Y_{1}<<Y_{2}$ and/or $\alpha \rightarrow 1$, the implication is that $\tilde{q}_{1}<q_{1}^{*}$.

Corollary 3 For spouse two, $\tilde{q}_{2}>q_{2}^{*}$ when $T \rightarrow 0$ and $Y_{2}>>Y_{1}$ and also if $\alpha \rightarrow 1$. In the case that $T>>$ but $Y_{2}<<Y_{1}$ and/or $\alpha \rightarrow 0$, the implication is that $\tilde{q}_{2}<q_{2}^{*}$.

Proposition 4 There is no crowding-out between the amount of transfer and the public transfers received by spouse one, in the situation of both marriage and divorce, if we do not consider that the grandparent takes into account the merit good.

Proof. Differentiating expression (15) and (13) in equilibrium, we can deduce the influence of the public transfer on the amount of transfer received in both marriage and divorce:

$$
\frac{\partial T^{*}}{\partial Z_{1}}=-\frac{\beta_{p} \frac{\partial^{2} W_{1}^{*}}{\partial T \partial Z_{1}}+g^{\prime \prime}\left(q_{1}^{*}\right) \frac{\partial q_{1}^{*}}{\partial T} \frac{\partial q_{1}^{*}}{\partial Z_{1}}+g^{\prime}\left(q_{1}^{*}\right) \frac{\partial^{2} q_{1}^{*}}{\partial T \partial Z_{1}}}{\Delta}
$$

In this case, public transfers change the total income. Increases in the income of the child, due to a public transfer, are not met with a reduction in private transfers from children. This finding has important implications for the effects of public transfer programs on the distribution of economic welfare.

In the case that $\frac{\partial^{2} W_{1}^{*}}{\partial T \partial Z_{1}}>0, \frac{\partial q_{1}^{*}}{\partial T}>0$ and $\frac{\partial q_{1}^{*}}{\partial Z_{1}}>0$ and $\frac{\partial^{2} q_{1}^{*}}{\partial T \partial Z_{1}}=0$,

$$
\begin{aligned}
& \frac{\partial T^{*}}{\partial Z_{1}} \geq 0 \text { if }\left|\beta_{p} \frac{\partial^{2} W_{1}^{*}}{\partial T \partial Z_{1}}\right| \leq\left|g^{\prime \prime}\left(q_{1}^{*}\right) \frac{\partial q_{1}^{*}}{\partial T} \frac{\partial q_{1}^{*}}{\partial Z_{1}}\right| \text { and } \\
& \frac{\partial T^{*}}{\partial Z_{1}}<0 \text { if }\left|\beta_{p} \frac{\partial^{2} W_{1}^{*}}{\partial T \partial Z_{1}}\right|>\left|g^{\prime \prime}\left(q_{1}^{*}\right) \frac{\partial q_{1}^{*}}{\partial T} \frac{\partial q_{1}^{*}}{\partial Z_{1}}\right|
\end{aligned}
$$

In the situation of divorce, we obtain the same results from the following expression: 


$$
\frac{\partial \tilde{T}}{\partial Z_{1}}=-\frac{\beta_{p} \frac{\partial^{2} \tilde{V}_{1}}{\partial T \partial Z_{1}}+g^{\prime \prime}\left(\tilde{q}_{1}\right) \frac{\partial \tilde{q}_{1}}{\partial T} \frac{\partial \tilde{q}_{1}}{\partial Z_{1}}+g^{\prime}\left(\tilde{q}_{1}\right) \frac{\partial^{2} \tilde{q}_{1}}{\partial T \partial Z_{1}}}{\Delta_{d}}
$$

Proposition 5 There is crowding out when public and inter-generational transfers affect, in the same way, the decisions of the agents in both marriage and divorce, since both transfers are part of the total income, even if the grandparent takes into consideration the "merit good".

Proof. Analysing our example we find that $\frac{\partial T^{*}}{\partial Z_{1}}<0$ and $\frac{\partial \tilde{T}}{\partial Z_{1}}<0$.

In marriage, from (17) it is straightforward to obtain that $\frac{\partial^{2} W_{1}^{*}}{\partial T \partial Z_{1}}=$ $\frac{\partial^{2} W_{1}^{*}}{\partial T^{2}}>0$, formally:

$$
\frac{\partial^{2} W_{1}^{*}}{\partial T^{2}}=\frac{\partial^{2} W_{1}^{*}}{\partial T \partial Z_{1}}=\frac{1}{2}\left[\frac{\partial W_{1}^{U P F}}{\partial T} \mu+\frac{\partial \tilde{V}_{1}}{\partial T} \frac{\alpha^{2}}{2 P_{1} \tilde{q}_{1}(1+\alpha)}+\Psi \frac{\partial W_{1}^{U P F}}{\partial W_{2}} \frac{\partial \tilde{V}_{2}}{\partial T}\right]
$$

where $\Psi=\left[\frac{\alpha^{2}}{P_{1} \tilde{q}_{1}(1+\alpha)}-\frac{1}{\Omega_{d 1}}\right]<0$ and $\mu=\left[\frac{\alpha^{2}}{2 P_{1} q_{1}^{*}}+\frac{(1-\alpha)}{2 P_{2} q_{2}^{*}}\right]>0 \rightarrow$ $\frac{\partial^{2} W_{1}^{*}}{\partial T \partial Z_{1}}=\frac{\partial^{2} W_{1}^{*}}{\partial T^{2}}>0$.

Considering (27) and (16) given that $\frac{\partial q_{1}^{*}}{\partial T}=\frac{\partial q_{1}^{*}}{\partial Z_{1}}$, because both transfers are part of the total income and $q_{i}^{*}=q_{i}^{*}\left(\Omega, \alpha, P_{i}\right)$. In our case, $\frac{\partial^{2} \tilde{q}_{1}}{\partial T \partial Z_{1}}=\frac{\partial^{2} \tilde{q}_{1}}{\partial T^{2}}$. We find that $\frac{\partial T^{*}}{\partial Z_{1}}<0$.

In divorce, we also determine that $\frac{\partial^{2} \tilde{V}_{1}}{\partial T \partial Z_{1}}=\frac{\partial^{2} \tilde{V}_{1}}{\partial T^{2}}$ and $\frac{\partial \tilde{q}_{1}}{\partial T}=\frac{\partial \tilde{q}_{1}}{\partial Z_{1}}$, because $\tilde{q}_{1}$ depends on total income. Taking into account (28) and (14) we obtain that $\frac{\partial \tilde{T}}{\partial Z_{1}}<0$.

Proposition 6 A public transfer, which is received by agent one in divorce, does not crowd out intergenerational transfer in marriage.

Proof. In this case, we suppose that $Z_{1}=0$ in marriage. Differentiating expression (15) in equilibrium, we find that $\frac{\partial T^{*}}{\partial Z_{1}}>0$. Formally,

$$
\frac{\partial T^{*}}{\partial Z_{1}}=-\frac{\beta_{p} \frac{\partial^{2} W_{1}^{*}}{\partial T \partial Z_{1}}}{\Delta}
$$

where $\frac{\partial^{2} W_{1}^{*}}{\partial T \partial Z_{1}} \neq \frac{\partial^{2} W_{1}^{*}}{\partial T^{2}}$. Differentiating expression (17) we obtain:

$\frac{\partial^{2} W_{1}^{*}}{\partial T \partial Z_{1}}=\frac{1}{2}\left[\frac{\partial \tilde{V}_{1}}{\partial T} \frac{\alpha^{2}}{2 P_{1} \tilde{q}_{1}(1+\alpha)}+\Psi \frac{\partial W_{1}^{U P F}}{\partial W_{2}} \frac{\partial \tilde{V}_{2}}{\partial T}\right]$. As we have noted earlier, $\Psi<0, \frac{\partial \tilde{V}_{1}}{\partial T}>0$ and $\frac{\partial \tilde{V}_{2}}{\partial T}>0$, which implies that $\frac{\partial^{2} W_{1}^{*}}{\partial T \partial Z_{1}}>0$. Therefore, when the public transfer increases, the inter-generational transfer also increases, even if it generates losses derived from the marriage for both spouses.

This result implies that the grandparent tries to compensate the son/daughter, equalizing the income of spouse one in both marriage and 
divorce situations. These findings cast doubt on the validity of testing alternative hypotheses concerning motivation for inter-vivo transfers, by studying the relationship between the recipient's pre-transfer income and the transfers received.

Finally, we analyse the effect that an exogenous transfer, from one ex-spouse to the other, has on the inter-generational transfer.

Proposition 7 The influence of the exogenous transfer from one exspouse to the the other on the amount of intergenerational transfer in the situation of marriage may be negative, which implies that the grandparent does not compensate the son/daughter in the situation of marriage. This result depends on the effect that the inter-generational transfer has on the welfare obtained by both spouses, and on the relationship between $\tilde{q}_{1}$ and $\tilde{q}_{2}$.

Proof. Differentiating expression (15) in equilibrium, we can deduce the influence of the exogenous transfer, from one ex-spouse to the the other, on the amount of transfer received in the situation of marriage:

$$
\frac{\partial T^{*}}{\partial r_{d}}=-\frac{\beta_{p} \frac{\partial^{2} W_{1}^{*}}{\partial T \partial r_{d}}}{\Delta}
$$

Subsequently, we determine the sign of $\frac{\partial^{2} W_{1}^{*}}{\partial T \partial r_{d}}$ from $(15) .{ }^{15}$ We obtain the following expression:

$$
\frac{\partial^{2} W_{1}^{*}}{\partial T \partial r_{d}}=\left[\left[\frac{\alpha\left(\Omega_{d 1}+\Omega_{d 2}\right)}{(2-\alpha)\left(\Omega_{d 1}\right)^{2}}\right] \frac{\partial \tilde{V}_{1}}{\partial T} \frac{\partial W_{1}^{U P F}}{\partial W_{2}}+\theta\left[\frac{\partial \tilde{V}_{1}}{\partial T}+\frac{\partial W_{1}^{U P F}}{\partial W_{2}} \frac{\partial \tilde{V}_{2}}{\partial T}\right]\right]
$$

where $\theta=\left[\frac{\alpha}{\tilde{q}_{1}} \frac{\partial \tilde{q}_{1}}{\partial r_{d}}+\frac{(1-\alpha)}{\tilde{q}_{2}} \frac{\partial \tilde{q}_{2}}{\partial r_{d}}\right]$.Therefore, when $\frac{\partial W_{1}^{*}}{\partial T}<0$ and $\theta>0$;

and also when $\frac{\partial W_{1}^{*}}{\partial T}>0$ and $\theta<0, \frac{\partial^{2} W_{1}^{*}}{\partial T \partial r_{d}}<0$ is satisfied. ${ }^{16}$

\section{Conclusions}

This study provides a basis for understanding partnering and parenting strategies by connecting two primary issues in family relationships: the relationships between spouses, and those between parents and children. ${ }^{17}$ In particular, we have analysed the effects that different sources of income have on welfare in both marriage and divorce situations, and on family decisions. To that end, we have assumed a family with three

\footnotetext{
${ }^{15}$ We must determine who is the donor and who is the recipient of the transfer in divorce. We suppose that agent one is the recipient and agent two is the donor.

${ }^{16}$ In the case that both $\frac{\partial W_{1}^{*}}{\partial T}$ and $\theta$ have the same sign, $\frac{\partial^{2} W_{1}^{*}}{\partial T \partial r_{d}}$ may be positive, therefore, $\frac{\partial T^{*}}{\partial r_{d}}>0$.

${ }^{17}$ Lundberg and Pollak (2007) point out these two areas for extended analysis.
} 
generations, with two adult generations (the donor and the recipient) living apart. The third generation being the children of the recipient.

The characterisation of the equilibrium of the game allows us to draw the following conclusions. First, our findings cast doubt on the validity of testing alternative hypotheses concerning motivation for inter-vivo transfers through the relationship between the recipient's pre-transfer income and the transfers received. This suggests that observing the relationship between the recipient's income and the inter-generational transfer is not sufficient to deduce that altruistic motives or exchange motives are at work. We analyse the effect that a public transfer, which can be received by the recipient of the inter-generational transfer in divorce, has on the decisions taken by the donor of the inter-generational transfer in marriage. One aspect to which the literature has not devoted particular interest, to date, has been the analysis of the effects on inter-generational transfers that certain policies (as in the case of child allowances or alimony) have on the decisions of the grandparent when the son/daughter is married. A government policy that implies higher allowances per child could increase the expected utility of divorced agents and thus lead to a re-allocation of resources in two-parent households and can affect the decisions taken by the grandparent in the same framework. As we have noted earlier, the grandparent tries to compensate the son/daughter by equalizing the income of spouse one in both marriage and divorce situations, when there is a public transfer in the situation of divorce, but not in marriage.

Secondly, we have found that there is crowding out when public and inter-generational transfers similarly affect the decisions of the agents in both marriage and divorce, since both transfers are part of the total income, even in the case that the grandparent takes into consideration the "merit good".

Thirdly, we have analysed the effect that an exogenous transfer made from one ex-spouse to the other, i.e., the alimony, may have on the inter-generational transfer in the situation of marriage. In this case, the grandparent does not always compensate the son/daughter in the situation of marriage. To determine the relationship between these two variables we must study the differences between the investment in child quality of both ex-spouses.

Finally, we have studied the welfare impact of changes in the intergenerational transfers. We have compared the changes along the utility possibilities frontier with the changes in the threat point. We have observed that, even when the investment in child quality in the situation of marriage is greater than in the situation of divorce, the inter-generational transfer may produce losses derived from the marriage. 
In closing, it should be noted that families have become more heterogeneous, thus making family relationships more complex. A wide range of different interactions can be studied using economic models of family relationships. Thus, modification of these kinds of models represents an important avenue for future research, for example, considering different game structures.

\section{Acknowledgements}

This paper was partially written while José Alberto Molina was Visiting Fellow at the Department of Economics of the University of Warwick (UK), to which he would like to express his thanks for the hospitality and facilities provided. Earlier versions of this paper have been presented at European Association of Labour Economists (EALE) Meeting-2006 (Praga, Czech Republic), at the British Society for Population Studies (BSPS) Conference-2006 (Southampton, UK), ant the I Workshop on Economics of the Family-2006 (Zaragoza, Spain), with all the comments made by the participants, particularly those of Ian Walker, being highly appreciated. Finally, the authors would like to express their thanks for the financial support provided by the Spanish Ministry of Education and Science (Project SEJ2005-06522 and Grant FPU), and by the BBVA Foundation. The usual disclaimer applies.

\section{References}

[1] Andaluz, J. and J.A. Molina 2007, How does the altruistic parental transfers affect the welfare gains of marriage?, Research in Economics 61, 1-9.

[2] Arrondel, L. and A. Laferrère, 2001, Taxation and wealth transmission in France, Journal of Public Economics 79, 3 - 33.

[3] Arrondel, L. and A. Masson, 2001, Family Transfers Involving Three Generations, Scandinavian Journal of Economics 103, 415 - 443.

[4] Barro, R.J. 1974, Are government bonds net wealth?, Journal of Political Economy 82, 1095 - 1117.

[5] Becker, G.S. 1965, A theory of the allocation of time, Economic Journal 7, $493-517$.

[6] Becker, G. S, 1974. A theory of social interactions, Journal of Political Economy 82, 1063 - 1094.

[7] Becker, G.S., 1981, Altruism in the family and selfishness in the Market place, Economica 48, 1-15.

[8] Becker, G. S. 1991. A Treatise on The Family, enlarged edition. Harvard University Press, Cambridge.

[9] Ben-Porath, Y. 1973, Economic analysis of fertility in Israel: point and counterpoint, Journal of Political Economy 81, s202 - s237. 
[10] Bergstrom, T. C., 1999, Systems of Benevolent Utility Functions, Journal of Economic Theory 1, 71-100.

[11] Bernheim, B. D., Shleifer, A. and L.H. Summers, 1985, The Strategic Bequest Motive, Journal of Political Economy 93, 1045-1076.

[12] Chami, R. 1998, Private Income Transfers and Market Incentives, Economica 65, 557- 580.

[13] Chami, R. and J.H. Fischer, 2000, Do private income transfers increase labor market risk?, Economics Letters 69, 143 -151.

[14] Chen, Z. and F. Woolley, 2001, A Cournot-Nash model of family decision making, The Economic Journal 111, 722-748.

[15] Chiappori, P.A., 1988, Rational Household Labor Supply, Econometrica 56, 63-90.

[16] Chiappori, P.A., 1992, Collective Labor Supply and Welfare, Journal of Political Economy 100, 437-467.

[17] Cox, D. 1987, Motives for private income transfer, Journal of Political Economy 95, 508 - 546.

[18] Cox, D. 1990, Intergenerational transfers and liquidity constraints, Quarterly Journal of Economics 105, 187 - 215.

[19] Cox, D., Eser, Z., and E. Jimenez, 1998, Motives for private transfers over the life cycle: an analytical framework and evidence for Peru, Journal of Development Economics 55, 57-80.

[20] Cox, D.and O. Stark 2005, On the demand for granchildren: tied transfers and the demonstration effect., Journal of Public Economics 89,1665-1697.

[21] Gale, W.G. and J.K. Scholz, 1994, Intergenerational transfers and the accumulation of wealth, Journal of Economic Perspectives 8, 145-160.

[22] Gronau, R. 1973, The effect of children on the housewife's value of time, Journal of Political Economy 81, s168 - s201.

[23] Guiso, L.and T. Japelli, 2002, Private Transfers, Borrowing Constraints and the Timing of Homeownership, Journal of Money, Credit, and Banking 34, 315-339.

[24] Güth, W., Offerman, T., Potters M. Strobel, H.A.A. and J. Verbon, 2004, Are Family transfers Crowded Out by Public Transfers?, Scandinavian Journal of Economics 104, 587-604.

[25] Jensen, R.T. 2003, Do private transfers 'displace' the benefits of public transfers? Evidence from South Africa, Journal of Public Economics 8, 89 -112.

[26] Kang, S. J. and M. Lee 2003, Analysis of private transfers with panel fixed effect censored model estimator, Economics Letters 80, $233-237$.

[27] Kang, S. J., Y. Sawada, 2003, Are Private Transfers altruistically 
motivated? The case of the Republic of Korea before and during the financial crisis, The Developing Economies XLI-4, 484 -501.

[28] Kotlikoff, L. J. and A. Spivak, 1981, The Family as an Incomplete Annuties Market, Journal of Political Economy 89, 372 -391.

[29] Kotlikoff, L.J. and L.H. Summers, 1981, The role of intergenerational transfers in aggregate capital accumulation, Journal of Political Economy 89, 32 -706.

[30] Rasul, I. 2006, The Economics of Child Custody, Economica 73, $1-25$.

[31] Laferrère, A., 1999. Intergenerational transmission models: a survey, Geneva Papers on Risk and Insurance: Issues and Practice 24, $2-26$.

[32] Lundberg, S. and R. Pollak, 1993, Separate spheres bargaining and the marriage market, Journal of Political Economy 101, 988-1010.

[33] Lundberg, S.and R.A. Pollak, 1994, Noncooperative Bargaining Models of Marriage, American Economic Review Papers and Proceeding 84, 132-137.

[34] Lundberg, S.and R.A. Pollak, 2007, The American Family and Family Economics, Journal of Economic Perspectives, forthcoming.

[35] Manser, M., and M. Brown, 1980, Marriage and Household Decision-Making: A Bargaining Analysis, International Economic Review 21, $31-44$.

[36] McElroy, M.B. and M.J. Horney, 1981, Nash-bargained Household Decisions: Toward a Generalization of the Theory of Demand, International Economics Review 22, 333 -349.

[37] Suen, W., Chan, W. and J. Zhang, 2003, Marital transfer and intrahousehold allocation: a Nash-bargaining analysis, Journal of Economic Behavior and Organization 52, 133-146.

[38] Villanueva, E., 2005, Intervivos Transfers and Bequests in three OECD Countries, Economic Policy 20. 